\title{
INFLUÊNCIA ESTRUTURAL SOBRE CAVERNAS EM FORMAÇÕES FERRÍFERAS, CARAJÁS-PA
}

\author{
Antônio Alessandro de Jesus Braga ${ }^{1}$; Alberto Pio Fiori ${ }^{1}$; \\ Daniele Freitas Gonçalves ${ }^{2}$; Francisco Ribeiro da Costa ${ }^{3}$ \\ 1- Programa de Pós-Graduação em Geologia, Universidade Federal do Paraná; 2 - Vale \\ 3 - Universidade Federal do Sul e sudeste do Pará, Campus Universitário de Marabá, IGE - Instituto de Geociências e Engenharia \\ Contatos: bragalessandro@hotmail.com; fiori@ufpr.br; daniele.freitas.goncalves@vale.com; frcgeo@unifesspa.edu.br
}

Recebido em 30 de novembro de 2016; aceito em 20 de junho de 2017

\begin{abstract}
Resumo: A pesquisa foi realizada no contexto geológico da Bacia Carajás, Província Mineral de Carajás no sudeste do Pará. Especificamente na mina de ferro N4E, alvo de exploração da empresa Vale. O objeto de estudo são cavernas hospedadas em formações ferríferas bandadas, bem como, em canga que é seu produto de alteração. Tem como principal objetivo avaliar a influência estrutural, processo este, que se mostra eficiente e importante para o desenvolvimento de uma caverna. Foram realizadas análises buscando entender de que forma estruturas descontínuas como, fraturas e bandamentos, controlam essas feições "pseudocársticas". Muito embora algumas cavernas pareçam não seguir nenhum padrão estrutural, em sua grande maioria encontram-se alongadas segundo planos de fraturas e bandamentos. Elas facilitam a percolação de fluidos que causa dissolução e/ou alteração da sílica, dando origem a pequenas cavidades que seriam as percussoras das cavernas. Os resultados mostraram que as cavernas tendem a se desenvolver segundo planos de fraqueza que facilitam a entrada de água e acarretam no colapso de blocos. No entanto, os resultados da comparação entre diagramas de rosetas gerados a partir dos canais de drenagem de primeira ordem, e das direções dos principais condutos das cavernas, apontaram para a não correlação com eventos tectônicos recentes, carecendo ainda de mais estudos neste sentido.
\end{abstract}

Palavras Chave: desenvolvimento de cavernas, fraturas, bandamentos

Abstract: STRUCTURAL INFLUENCE ON IRON FORMATION CAVES, CARAJÁS, PA. The research was carried out in the geological context of the Carajás basin, Carajás Mineral province, southeastern Pará, specifically in the N4E iron ore mine, which has been exploited by Vale. The object of study are caves hosted by banded iron formations, as well as by canga, which is their alteration product. This work aims mainly to evaluate the structural influence, which is an efficient and important process for a cave development. Analysis were performed in order to understand how discontinuous structures, such as fractures and bundles control these "pseudocarstic" features. Although some caves seem to follow no structural pattern, most of them are elongated by fracture planes and banding. They facilitate the percolation of fluids that cause dissolution and/or alteration of silica, giving rise to small cavities that would be the percussors of the caves. The results showed that the caves tend to develop under planes of weakness that facilitate the entry of water and lead to the collapse of blocks. However, the results obtained by the comparison of rosette diagrams generated from the first-order drainage channels and the directions of the main conduits of the caves showed to be non-correlated with recent tectonic events, and still need further studies in this sense.

Keywords: development of caves, fractures, banding

\section{INTRODUÇÃO}

De acordo com a União Internacional de Espeleologia (UIS): "Caverna consiste em uma abertura natural formada em rocha abaixo da superfície do terreno, larga o suficiente para a entrada de uma pessoa, com ou sem abertura identificada, popularmente conhecida como cavidade". São feições que ocorrem em larga escala nos calcários e arenitos. Contudo, Formações Ferríferas Bandadas (FFB) e canga, também comportam inúmeras cavernas. Em Carajás elas ocorrem principalmente na interface entre os dois.

As FFB são compostas por intercalação de bandas de coloração escura representada por óxidos de ferro, hematita e magnetita e por bandas claras de chert e avermelhadas de jaspe (Costa, 2006). A canga (laterita) é proveniente do processo de alteração do minério de ferro, que por sua vez, é produto de alteração da FFB. Ocorre geralmente recobrindo a FFB, sendo composta por clastos angulosos principalmente de hematita cimentados por uma matriz de consistência argilosa constituída essencialmente por hematita e goetita (Maurity \& Kotschoubey, 1995). Sua formação está ligada a processos de laterização com redistribuição de Fe e Al associado a variações climáticas (Dutra, 2013). De acordo com Vasconcelos (1992) o início da laterização na Amazônia se deu em torno de $65 \mathrm{Ma}$, em seguida a região de Carajás passou por eventos de soerguimento e posterior reativação de processos erosivos (Souza e Kotschoubey, 1991).

Em sua grande maioria, as cavernas ocorrem em cotas altimétricas entre 600 e $700 \mathrm{~m}$, geralmente nas quebras de relevo: borda de lagoas; cabeceiras e borda de drenagens; e nas bordas dos platôs, incluindo-se a alta, média e baixa vertente Piló e Auler (2009). Quanto à gênese, os principais processos identificados por Dutra (2013) são erosão, lixiviação, dissolução e biogênese.

O objetivo principal deste trabalho é mostrar de que forma as estruturas descontínuas tais como fraturas, falhas e bandamentos, controlam o desenvolvimento de cavernas em Formações Ferríferas bandadas.

A hipótese aceita até o momento relata que a influência de estruturas descontínuas sejam elas 
recente ou não, pode ser esperada por conta da facilidade de percolação de fluidos nessas zonas de fraqueza. Esse processo implica na completa dissolução e/ou alteração de minerais menos resistentes, a se destacar as bandas formadas basicamente por sílica (Braga, em preparação; Cabral et al., 2016). No entanto, não é possível afirmar que elas se formariam apenas por sofrer tal influência, pois algumas cavernas se desenvolvem a partir da porosidade primária ou da acomodação de blocos aglutinados.

\section{GEOLOGIA REGIONAL}

A Província Mineral de Carajás localizada no sudeste do Pará é uma das mais importantes do mundo principalmente em termos metalogenéticos, pois é dotada de inúmeras mineralizações principalmente de ferro. Possui idade arqueana e está inserida no Cráton Amazônico, sendo constituída pelo Domínio Carajás a norte, que corresponde à Bacia Carajás e Subdomínio de Transição, e pelo Domínio Rio Maria na porção sul (Dall'Agnolet al., 2006; Feio, 2011).

As cavernas a serem analisadas estão situadas principalmente na Formação Carajás, inserida no Grupo Grão Pará. Este grupo faz parte do preenchimento da Bacia Carajás e se constitui pelas formações Parauapebas, Carajás e Igarapé Cigarra (Figura 1).

\begin{tabular}{|c|c|c|c|c|}
\hline ÉON & ERA & & UNIDADE & DESCRIÇÃO \\
\hline 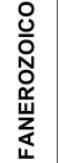 & 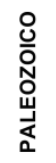 & \multicolumn{2}{|c|}{ CORPOS MÁFICOS INTRUSIVOS } & Diques e soleiras de diabásio \\
\hline \multirow{3}{*}{ 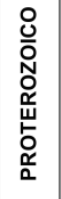 } & \multirow{3}{*}{ 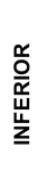 } & \multicolumn{2}{|c|}{ GRANITO SERRADOS CARAJÁS } & Granitos a anfibólios e/ou biotita \\
\hline & & \multicolumn{2}{|r|}{ GABRO SANTAINÊS } & Gabro grosseiro hidrotermalizado \\
\hline & & \multicolumn{2}{|r|}{ FORMAÇĀO IGARAPÉ AZUL } & $\begin{array}{l}\text { Arenitos com niveis conglomeráticose } \\
\text { siltitos intercalado }\end{array}$ \\
\hline \multirow{8}{*}{\multicolumn{2}{|c|}{ 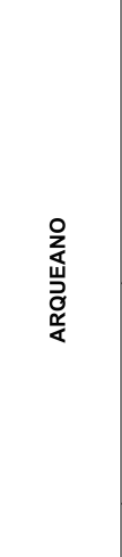 }} & \multirow{4}{*}{ 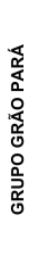 } & Formação Igarapé Boa Sorte & $\begin{array}{l}\text { Siltitos e folhelhos carbonáticos com } \\
\text { arenitos subordinado }\end{array}$ \\
\hline & & & Formação Igarapé Cigarra & $\begin{array}{l}\text { Basaltos, tulfos, BIF, chert, quartzo- } \\
\text { wackes e quartizo arenito }\end{array}$ \\
\hline & & & Formação Carajás & BIF's com soleiras de basalto \\
\hline & & & Formação Parauapebas & Basaltos e riolitos \\
\hline & & \multirow{3}{*}{ 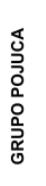 } & Formação Gameleira & Meta-wackes e meta-siltitos \\
\hline & & & Formação Corpo 4 & BIF's (sulfeto) e xistos \\
\hline & & & Formação Bueno & Anfibolitos BIF's (óxido) \\
\hline & & \multicolumn{2}{|r|}{ COMPLEXO XINGU } & $\begin{array}{l}\text { Gnaisse granodioriticos a tonaliticos, } \\
\text { anfibolitos e trondjemito }\end{array}$ \\
\hline
\end{tabular}

Figura 1. Coluna cronoestratigráfica de parte da Serra Norte (Bacia Carajás). Modificado de Macambira et al. (1990).
A Formação Parauapebas é representada por rochas vulcânicas máficas e félsicas datadas de 2758 \pm 39 Ma por (Gibbs et al. 1986). A Formação Carajás está em contato com a Formação Parauapebas e mostra intercalações entre as rochas vulcânicas máficas e a FFB de acordo com Gibbs \& Wirth 1990. As FFB são predominantes nessa formação sendo descritas como jaspilito meso e microbandado formado por bandas de jaspe (chert impregnado por hematita microcristalina) e óxidos de ferro depositados em 2.751 \pm 4 Ma (Krymskyet al. 2002). A Formação Igarapé Cigarra, proposta por Macambira et al. (1990), possui contato concordante sobre a Formação Carajás, com as camadas de BIF's recobertas por rochas máficas com intercalações de tufos, seguidos por sedimentos clásticos e químicos (Macambira 2003). É composta por basaltos alterados hidrotermalmente com textura ígnea preservada semelhante aos da Formação Parauapebas, além de serem indistinguíveis química e mineralogicamente. No entanto, os da Formação Parauapebas parecem ser mais magnesianos que os da Formação Igarapé Cigarra.

De acordo com Pinheiro \& Holdsworth (2000) Carajás teria sido alvo de cinco episódios tectônicos: transpressão sinistral dúctil, caracterizada pela formação da trama dúctil E-W, entre 3.0 e $2.8 \mathrm{Ga}$; transpressão sinistral, na qual a trama E-W foi submetida a reativação rúptil; transtensão destral, onde se formaria os sistemas Carajás e Cinzento e também seria responsável pela instalação da Falha Carajás logo após $2.7 \mathrm{Ga}$; em 2,5 Ga uma transpressão sinistral gera a inversão nas rochas da Bacia Carajás; e no Paleoproterozoico (1,88 Ga), um evento extensivo ou transtensivo possibilitou a intrusão de plútons graníticos e de diques.

Do ponto de vista tectônico recente, as principais estruturas da região de Carajás são representadas por três feixes de falhas transcorrentes $E-W$ e dois feixes de falhas normais N-S (Bemerguyet al. 2000). Além de descontinuidades NE e NW interpretadas por Costa et al. (1991) como estruturas transpressivas e transtensivas, respectivamente em resposta ao movimento principal de caráter transcorrente destral. Tais estruturas controlam os canais de drenagem mais jovens e perturbam o curso de rios mais antigos condicionando a geração de anomalias de drenagem.

\section{LOCALIZAÇÃO E ACESSO}

A área de pesquisa encontra-se localizada na Serra do Carajás mais precisamente Serra Norte, inserida na Bacia Carajás, Província Mineral de 
Carajás região sudeste do Pará nas adjacências do município de Parauapebas. $\mathrm{O}$ acesso pode ser feito através de transporte aéreo até o aeroporto de Carajás, por via férrea ou ainda por via terrestre, partindo do município de Marabá no sudeste do Pará, pela BR-155 por $100 \mathrm{~km}$ até Eldorado dos Carajás, prosseguindo a partir daí pela PA-275 por 65 $\mathrm{km}$ até Parauapebas, em seguida segue pela rodovia Raimundo Mascarenhas em um percurso de $30 \mathrm{~km}$ até a entrada das minas (Figura 2).

As cavernas estão associadas a grandes zonas de alinhamentos estruturais, representadas por falhas transcorrentes sinistrais e destrais, as quais correspondem a zonas de cisalhamento. Observa-se que elas se concentram em três áreas distintas: porção norte; porção centro-oeste; e na parte sudeste do mapa. Entretanto, para este trabalho será considerada apenas a área de ocorrência na porção norte (Figura 2).

\section{MATERIAIS E MÉTODOS}

A descrição espacial da área de ocorrência de cavernas, foi realizada a partir da análise de imagens aéreas de radar, Lidar (Light Detection And Ranging) para geração dos Modelos Digitais de Terreno (MDT), imagens da missão Shuttle Radar Topography Mission (SRTM), além de imagens do sensor LANDSAT 8.

A drenagem foi extraída de forma automática no software Global Mapper a partir de imagens de radar e corrigida manualmente com auxilio de curvas de nível e da imagem de sensor LANDSAT 8. As principais direções dos canais de drenagem de menor ordem, de acordo com o conceito de hierarquia de Strahler (1952), foram comparadas com as direções dos condutos das cavernas, traçados no ArcGIS 10.1.As campanhas de campo tiveram como objetivo o mapeamento geoestrutural. Os dados coletados foram transformados em mapas geoestruturais e diagramas de roseta.

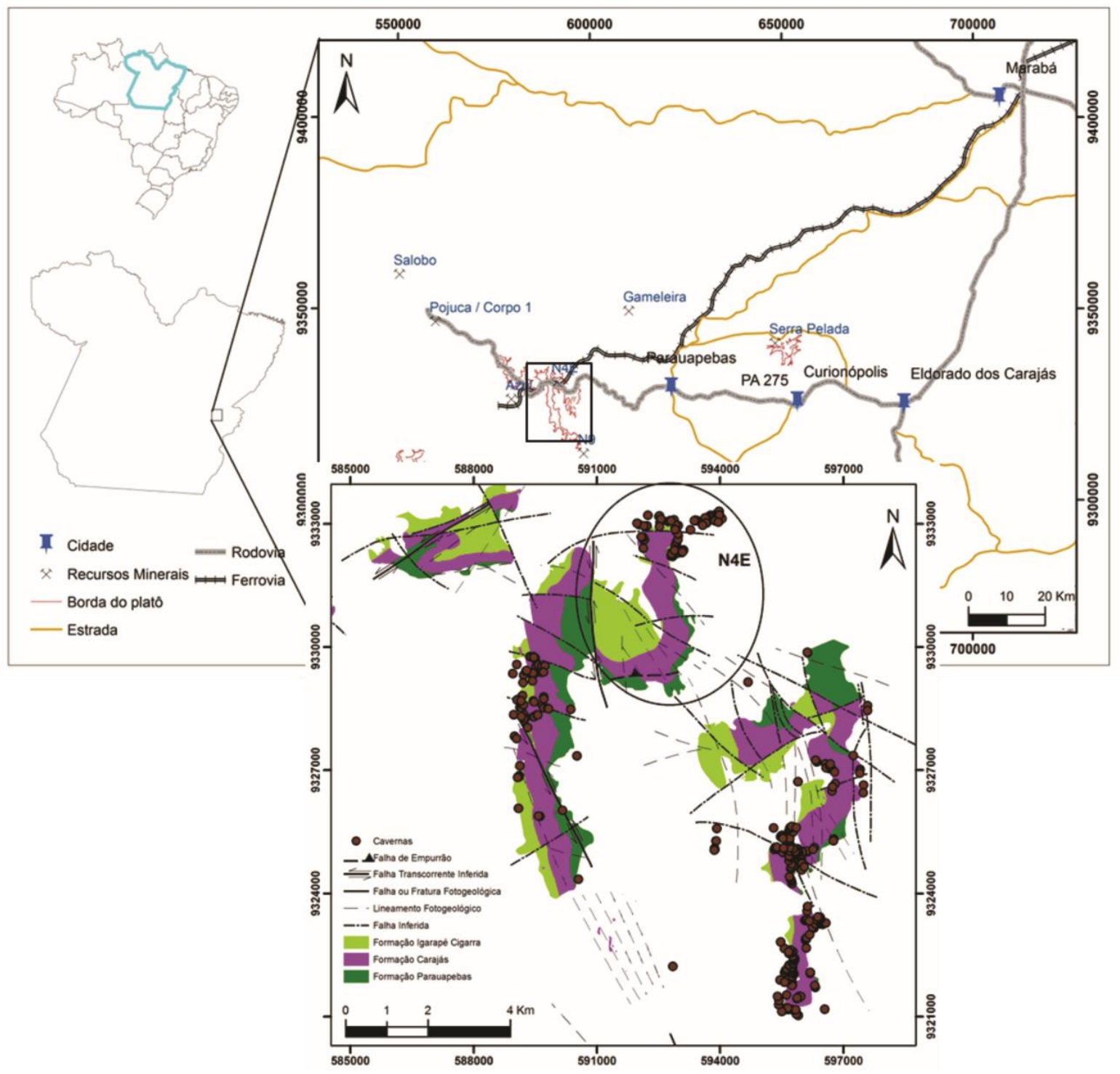

Figura 2. Mapa de localização associado ao mapa geológico de Resende e Barbosa (1972) na escala de 1:25000. 


\section{RESULTADOS E DISCUSSÕES}

Os resultados apresentados são referentes à análise da rede de drenagem, bem como, seus lineamentos e a caracterização estrutural de cinco cavernas desenvolvidas em FFB e/ou canga.

\subsection{Análise da Drenagem}

A Figura 3 apresenta o mapa de drenagem da área. As principais diferenças estão na angularidade e orientação dos canais.

$\mathrm{Na}$ porção centro sul da área, nota-se que os canais não seguem orientação preferencial. Nas porções noroeste e sudeste é possível observar que os canais principais estão orientados segundo a direção NW-SE e os de menor ordem na direção NESW. Quanto ao ângulo de confluência, geralmente se interconectam sob alto ângulo, por vezes formando ângulos retos. Existe ainda uma grande diferença em relação à densidade da drenagem. A porção norte, apresenta-se de forma pouco densa diferente do padrão geral do mapa. Isso se deve ao contraste de impermeabilidade e aplainamento da região. Em relação ao padrão de drenagem, no geral, nota-se uma variação de treliça a retangular, o que denota intenso controle estrutural na região.

\subsection{Lineamentos de drenagem}

Os lineamentos indicam forte controle estrutural influenciando a disposição dos canais, pois, ocorrem de forma continua segundo a direção N-S, levemente arqueados para NE. Estão encaixados nos grandes vales N-S que a região de Carajás apresenta, os quais são intensamente entalhados pela rede drenagem, coincidentes com feições denominadas splays de falha, feições estas, intimamente relacionadas à formação da Falha Carajás. Quanto às rosetas, os traços de drenagem ocorrem em direções variadas para comprimento e frequência absoluta (Figura 4).

O diagrama de rosetas representado pela Figura 5 a corresponde às medidas de 271 condutos de 94 cavernas localizadas no corpo de minério N4E. É possível observar que existem condutos nas direções NE-SW, NW-SE, N-S e E-W, sendo este último mais frequente. No diagrama da Figura $5 b$, estão plotadas 1511 medidas de lineamentos correspondentes aos canais de drenagem de primeira ordem, os quais teoricamente teriam sido gerados por eventos tectônicos mais recentes (Salamuni et al. 2004). Como no diagrama anterior, as famílias também ocorrem nas quatro direções. No entanto, as direções de maiores desenvolvimento se orientam segundo E-W e N-S. Assim, nota-se uma relativa dispersão nos dois diagramas, onde é possível comparar apenas a família E-W, a qual predomina em ambos.

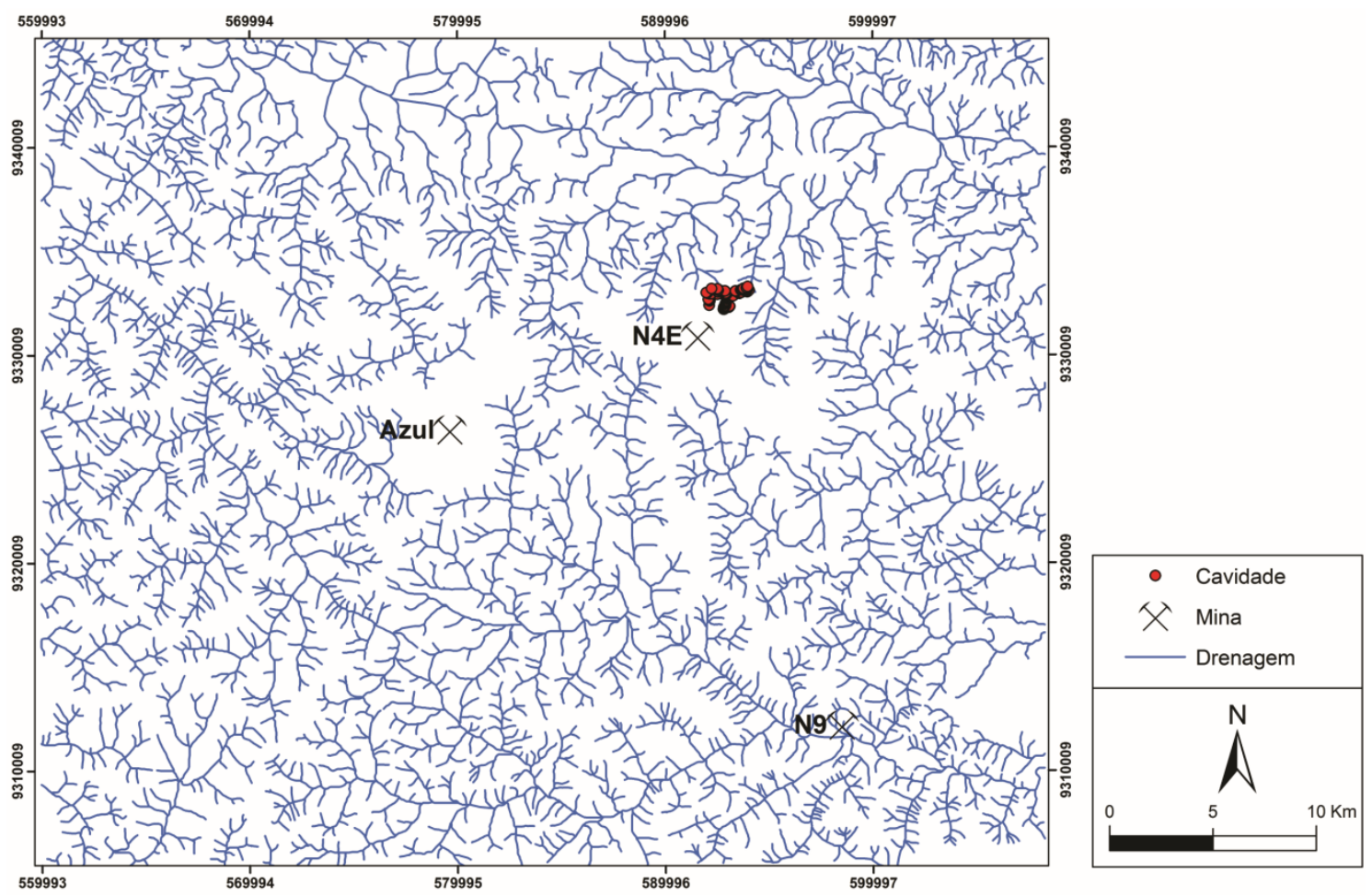

Figura 3. Mapa de drenagem 

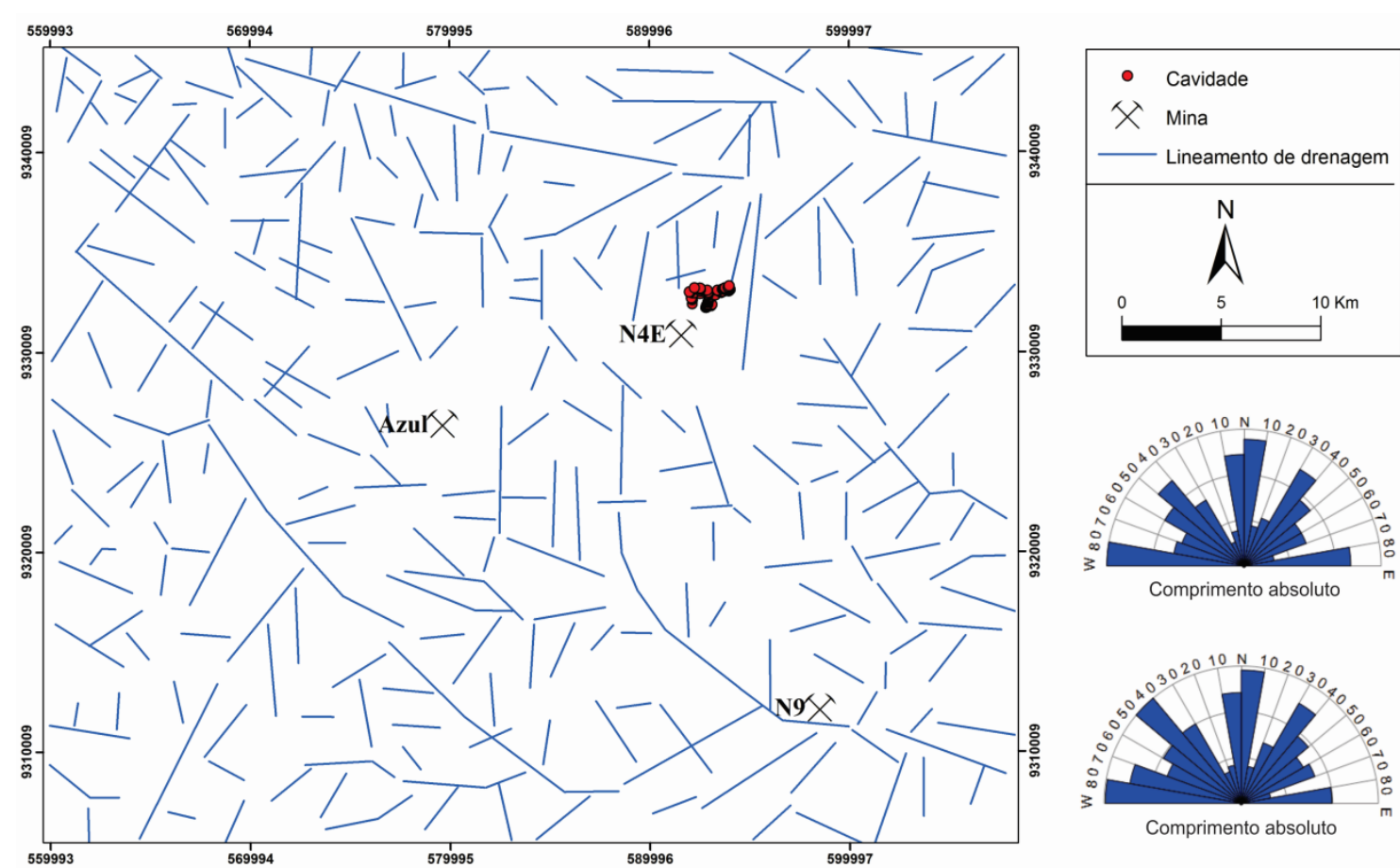

Figura 4. Mapa de lineamentos de drenagem.

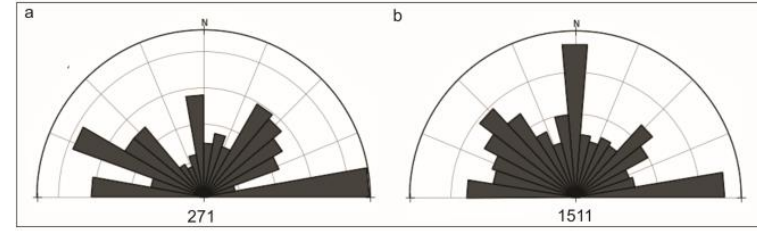

Figura 5. Diagrama de rosetas obtido a partir de 271 direções de condutos de 94 cavernas em a. Em b, o mesmo diagrama, agora com 1511 direções de canais de primeira ordem da rede de drenagem.

Como relatado por Bemerguy et al. (2000) as principais estruturas tectônicas recentes da região de Carajás são feixes de falhas E-W e N-S, o que é comprovado pelo diagrama da Figura 5.

\subsection{Caracterização geoestrutural das cavernas}

As cavernas aqui avaliadas representam uma pequena parte das cavernas de Carajás. Encontramse hospedadas principalmente em minério de ferro e canga, no entanto, estão presentes também em rochas máficas, muito embora, em menor quantidade.

Foi realizada a caracterização geoestrutural das seguintes cavernas: N4E 0014; N4E 0021; N4E 0033; N4E 0092; e N4E 0093 (Figura 6).

\subsubsection{Caverna N4E_0014}

Possui projeção horizontal de $102 \mathrm{~m}$. Apresenta duas entradas, uma a oeste (Figura 7a), a qual tem cerca de 1,3 $\mathrm{m}$ de altura por $2 \mathrm{~m}$ de extensão em um afloramento de aproximadamente $8 \mathrm{~m}$ de altura. A segunda está localizada a leste, (Figura 7b), desenvolvida em um paredão amplo com cerca de $10 \mathrm{~m}$ de altura por $18 \mathrm{~m}$ de extensão. A caverna possui forma irregular, no entanto, é controlada por famílias de fraturas. $O$ piso mostra alguns blocos abatidos e ocorre inclinado no sentido da vertente, tende a aumentar sua inclinação a partir da entrada em direção ao terço mais distal. As paredes são irregulares, bem como, os pilares.

A caverna é hospedada em FFB (perfaz cerca de $80 \%$ da área total) e canga. A primeira possui bandas de hematita que variam de milimétricas a centimétricas, intercaladas com espaços vazios ou impregnados por goethita (Figura 8a e 8b). Com o avanço em direção ao interior da caverna tende a se tornar ainda mais avermelhada, por conta da presença mais intensa deste material. A canga que corresponde a aproximadamente $20 \%$ possui coloração avermelhada e ocorre principalmente nas porções mais elevadas. Em alguns pontos nota-se a presença de clastos subangulosos de tamanho centimétricos, imersos em uma matriz terrígena avermelhada. Em algumas porções é possível notar uma leve orientação dos clastos de hematita. Na porção distal as duas litologias não apresentam contatos nítidos, sendo por vezes, difícil definir um limite entre estas. É comum encontrar bolsões de canga dentro da FFB, no entanto, a canga geralmente se dá nas porções mais elevadas. 


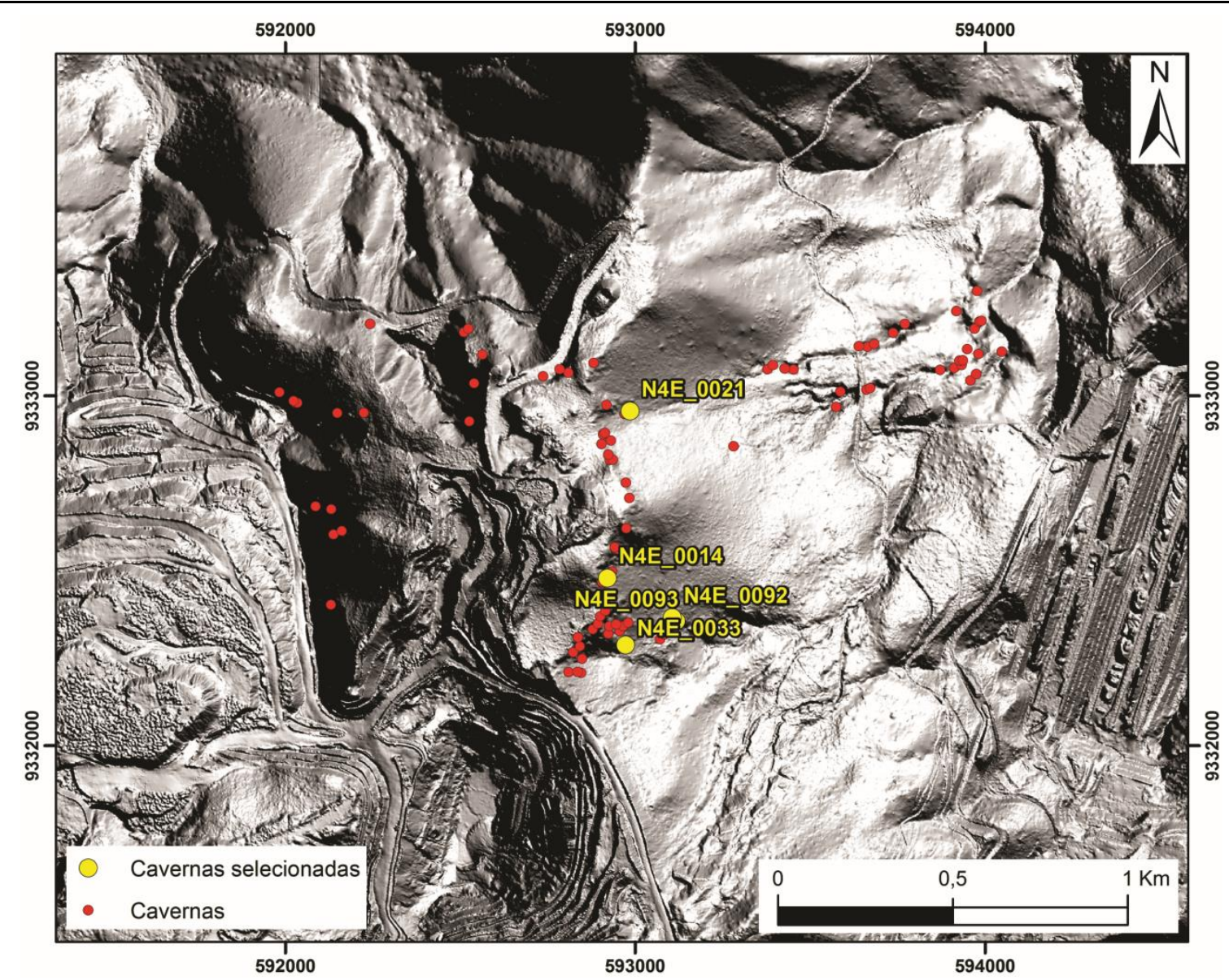

Figura 6. Mapa de localização das cinco cavernas selecionadas.
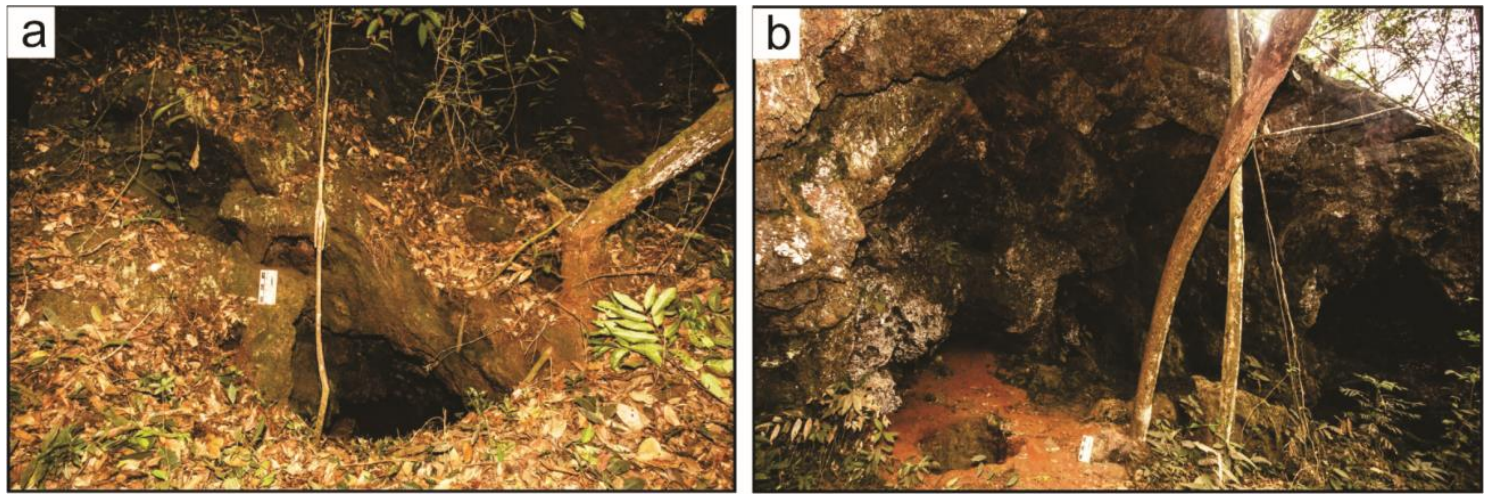

Figura 7. Fotos das duas entradas. a) entrada localizada a oeste. b) entrada situada na porção leste da caverna.

Apesar de a caverna apresentar forma irregular (Figura 9a), uma análise das direções de fraturas e bandamentos indica controle estrutural marcante. $O$ bandamento ocorre na direção NW-SE com mergulho moderado para NE (Figura 9b). As fraturas mostram duas famílias principais, uma com direção NE-SW subvertical e outra seguindo a direção NW-SE (Figura 9c).

Assim é possível comparar a direção do bandamento, bem como, da segunda família de fraturas com a orientação principal de desenvolvimento da caverna que é NW-SE. A família principal de fraturas é coincidente com a direção secundária de desenvolvimento, a qual seria NE-SW. A fratura N40\%/60SE possivelmente controlou a interligação entre dois salões outrora separados (Figura 8c). A intersecção de famílias de fraturas com o bandamento gera instabilização do maciço rochoso, o que acarreta em desplacamentos e ampliação da caverna. Na porção distal, fraturas de direção $\mathrm{N} 40$ o subvertical estão presentes na FFB, bem como, na canga, (Figura 8d). É bastante comum observar dobras na FFB como mostram as Figuras $8 \mathrm{e}$ e 8f. Estas são produto de deformação e ocorrem de forma variada, sem seguir um padrão definido. 

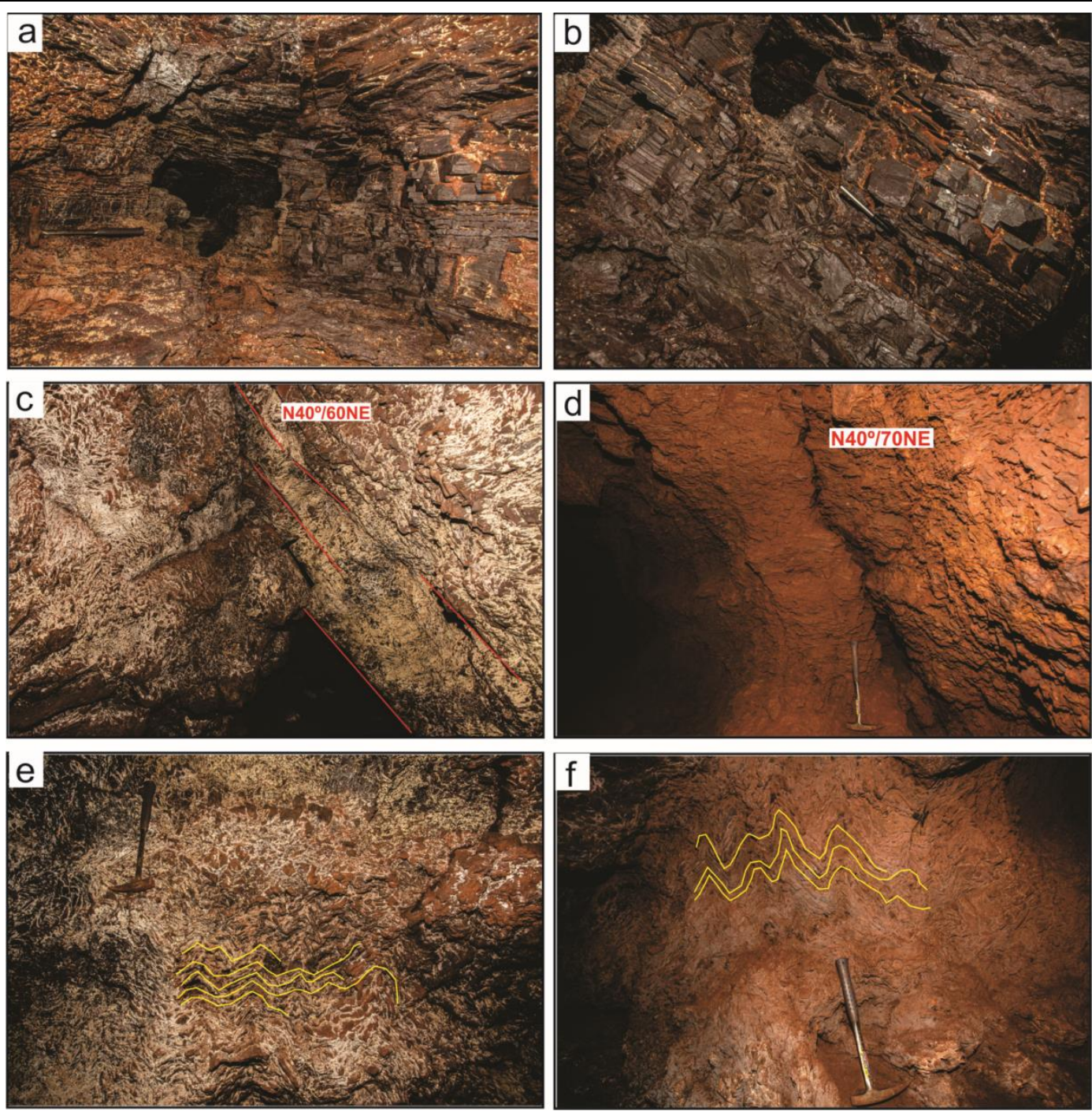

Figura 8. Feições litoestruturais. a) e b) fotos da FFB com bandas de hematita milimétricas a centimétricas, nos espaços entre as bandas nota-se impregnação por material argiloso. c) fratura N40\%/60NE marcando a formação de um conduto que interliga duas galerias. d) fratura N4O\%/7ONE na canga. e) ef) dobras na FFB.

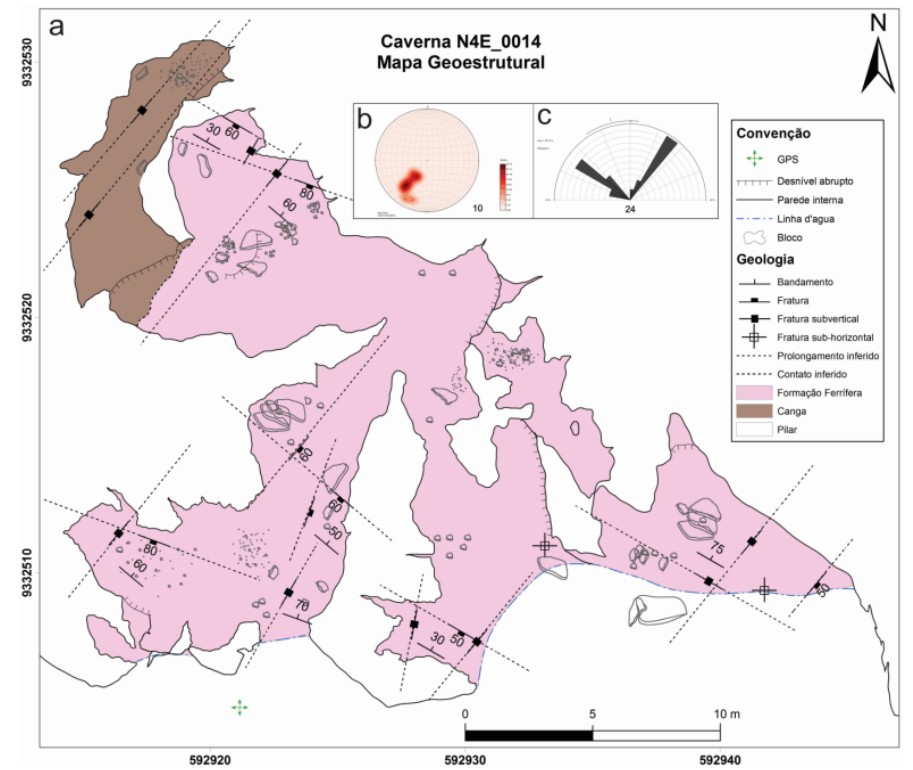

Figura 9. a) mapa geoestrutural da caverna N4E_0014. b) diagrama de polos correspondente a 10 medidas de bandamento. c) diagrama de rosetas com 24 medidas de fraturas. 


\subsubsection{Caverna N4E_0021}

Possui $41 \mathrm{~m}$ de projeção horizontal eapresenta uma única entrada (Figura 10). A qual segue para um salão de teto baixo, paredes irregulares e piso plano no terço médio, tornando-se inclinado na parte distal, onde o teto se torna mais alto. Matacões abatidos de FFB são observados em toda sua extensão, além de fragmentos hematíticos espalhados por todo o piso.

Litologicamente é composta por FFB (Figura 11a e $11 \mathrm{~b}$, respectivamente), onde predominam bandas milimétricas a centimétricas de óxido e hidróxido de ferro, por vezes impregnadas por pigmentação esbranquiçada e/ou goethita. Essas bandas frequentemente se apresentam dobradas. $\mathrm{Na}$ porção distal encontram-se parcialmente alterada com neoformações goethíticas/hematíticas.

A entrada da caverna se formou ao longo do eixo de uma dobra com atitude N 280 (não foi possívelmedir o caimento). Na parede logo na entrada, encontra-se uma dobra do tipo Chevron com eixo $\mathrm{N} 350^{\circ}$ e caimento de $45^{\circ}$ para NW (Figura 11c). Analisando a planta da caverna (Figura 12a), nota-se que os condutos são controlados pela presença de fraturasque formam pares conjugados de direção $\mathrm{N} 60^{\circ} /$ subvertical e $\mathrm{N} 160^{\circ} / 70 \mathrm{NE}$ (Figura 12c) que ocorrem seccionando $\mathrm{o}$ bandamento (Figura 11d). Este possui direção NW-SE com mergulho variando para SW e NE (Figura 12b). Algumas fraturas intersectam as duas litologias a exemplo da caverna anterior. A principal direção de desenvolvimento se da segundo a direção $\mathrm{N}^{\circ} 0^{\circ}$, na qual é possível observar algumas fraturas preenchidas por material silicoso (Figura 11e e 11f).

\subsubsection{Caverna N4E_0033}

Possui 120,4 m de projeção horizontal. Apresenta duas entradas, uma pequena com cerca de $1,5 \mathrm{~m}$ de altura e outra mais ampla, suspensa. $A$ entrada menor (Figura 13a) progride para um conduto, enquanto a entrada suspensa (Figura 13b) dá acesso a um salão. O piso nos setores iniciais é plano, tornando-se mais inclinado para o interior da caverna. As paredes são irregulares e o teto é baixo na entrada menor, ao passo que se torna mais alto nos terços médio e distal. Matacões abatidos de FFB são observados em toda sua extensão.

A caverna está hospedada exclusivamente em FFB, com bandamento bastante evidente. As bandas de óxido de ferro são variam de milimétricas a centimetricas intercaladas com espaços vazios, proveniente da remoção de sílica. A Figura 14 apresenta as principais feições litoestruturais da caverna.

No mapa geoestrutural (Figura 15a) nota-se que a caverna se desenvolve segundo uma oientação principal NW-SE. O terço inicial é controlado por uma dobra com eixo orientado segundo NW-SE.O bandamento apresenta direção variando para E-W, NE-SW e NW-SE com mergulhos moderados (Figura 15b). As fraturas possuem direção geral NE-SW e NW-SE com mergulho moderado a alto, como mostra o diagrama de rosetas na Figura 15c, ocorrem sempre cortando o bandamento (Figura $14 a, 14 b, 14$ c e 14d). Essa intersecção gera instabilidade no maciço, pois em algumas porções as fraturas fragmentam o bandamento podendo causar desplacamento. Na porção mais distal da caverna, fraturas subverticais abertas $\mathrm{N} 40^{\circ}$ são preenchidas por material ferruginoso (Figura 14e e 14f) e possibilitam fluxo de água. Dobras também são evidenciadas principalmente nas paredes (Figura 14g e $14 \mathrm{~h}$ ).

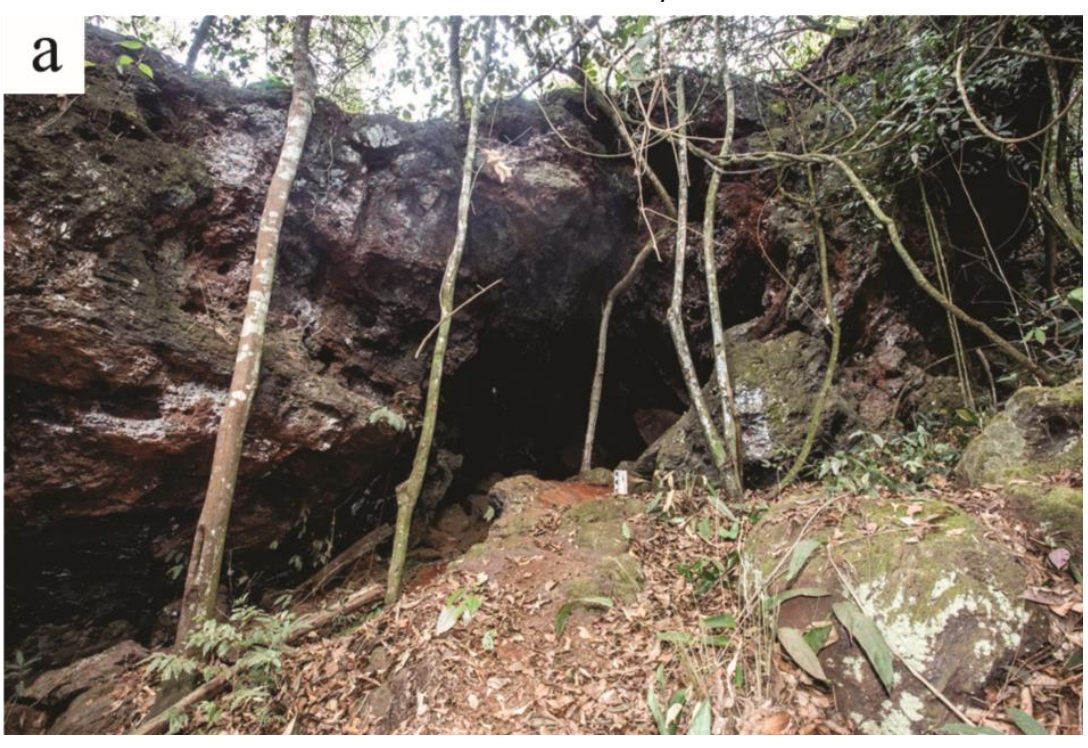

Figura 10. Foto da entrada da caverna N4E_0021. 

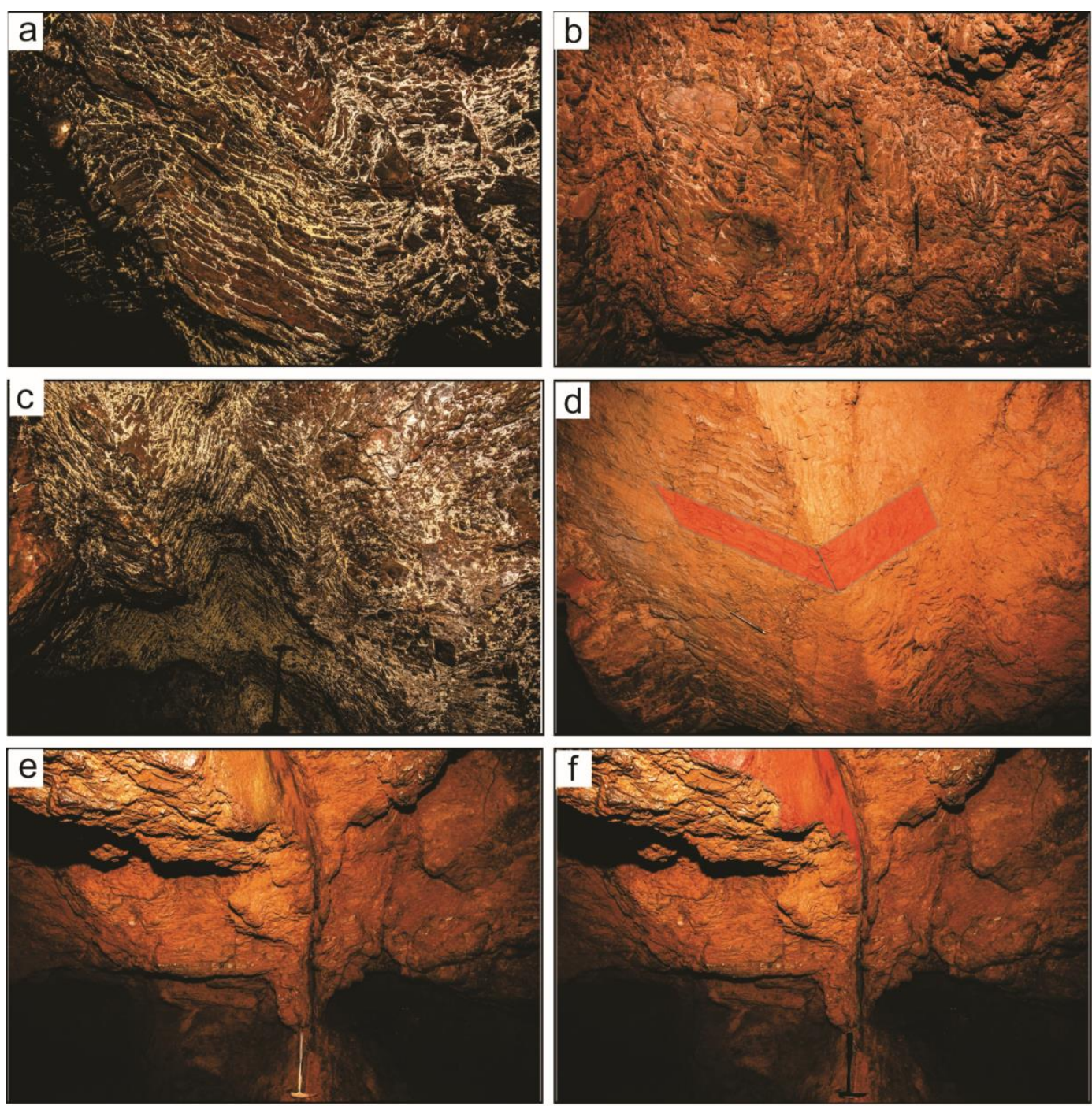

Figura 11. Feições litoestruturais. a) foto da FFB com bandamento levemente arqueado. b) foto da canga com maior nível de deformação e alteração. c) dobras em Chevron no mineiro de ferro na entrada. d) planos de fraturas ortogonais seccionando o bandamento. e) e f) plano de fratura subvertical.

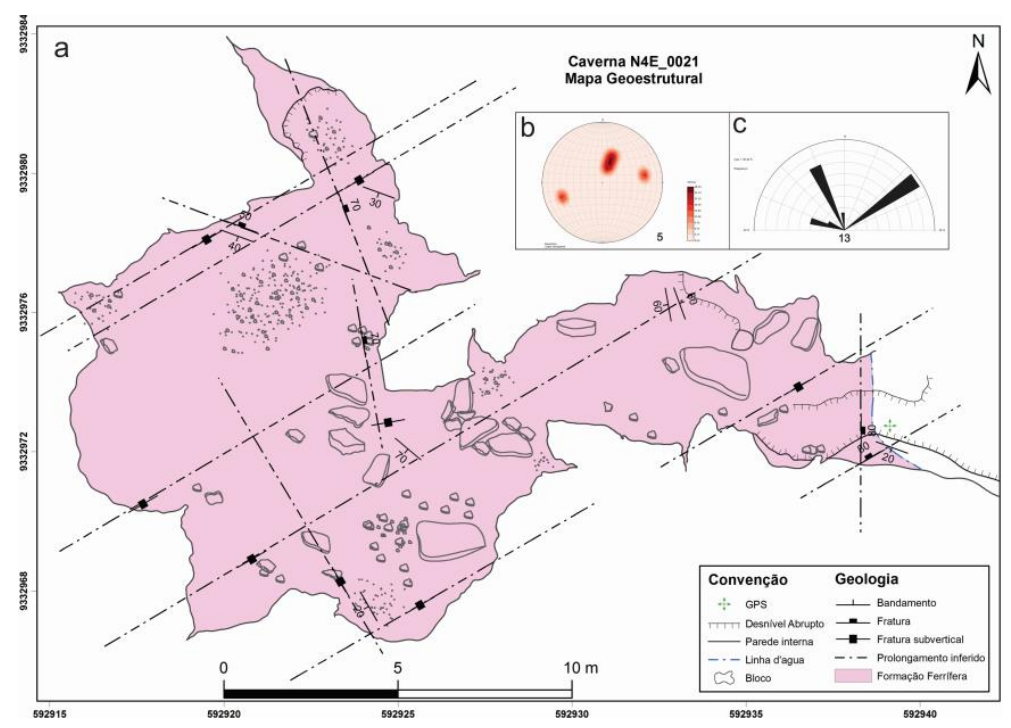

Figura 12. Em a, o mapa geoestrutural da caverna N4E_0021. b) diagrama de polos correspondente a 5 medidas de bandamento. c) diagrama de rosetas com 13 medidas de fraturas. 

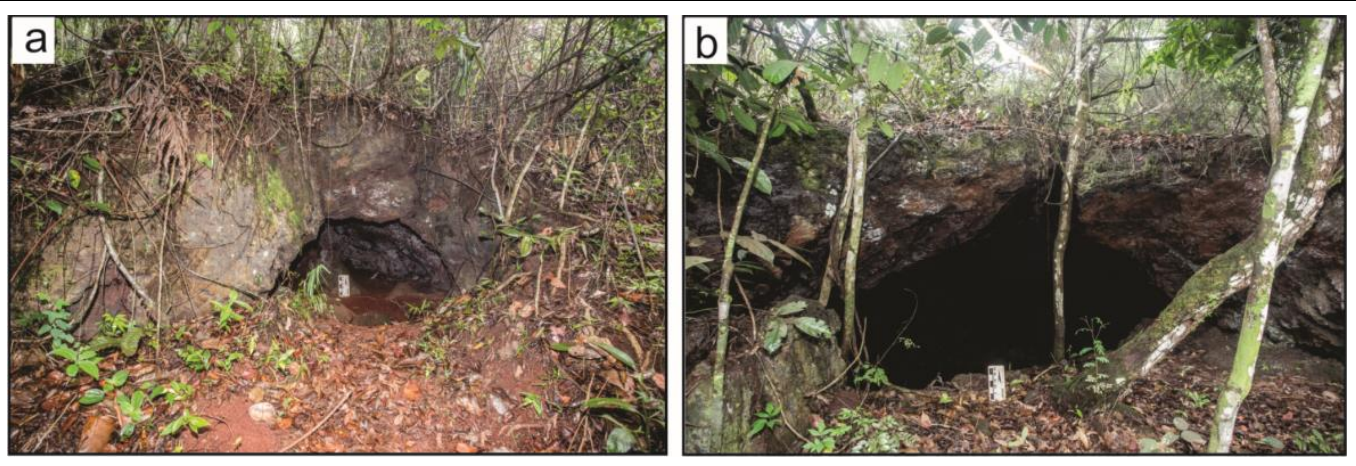

Figura 13. Fotos da entrada da caverna. a) entrada principal com pequeno desenvolvimento. b) entrada suspensas.
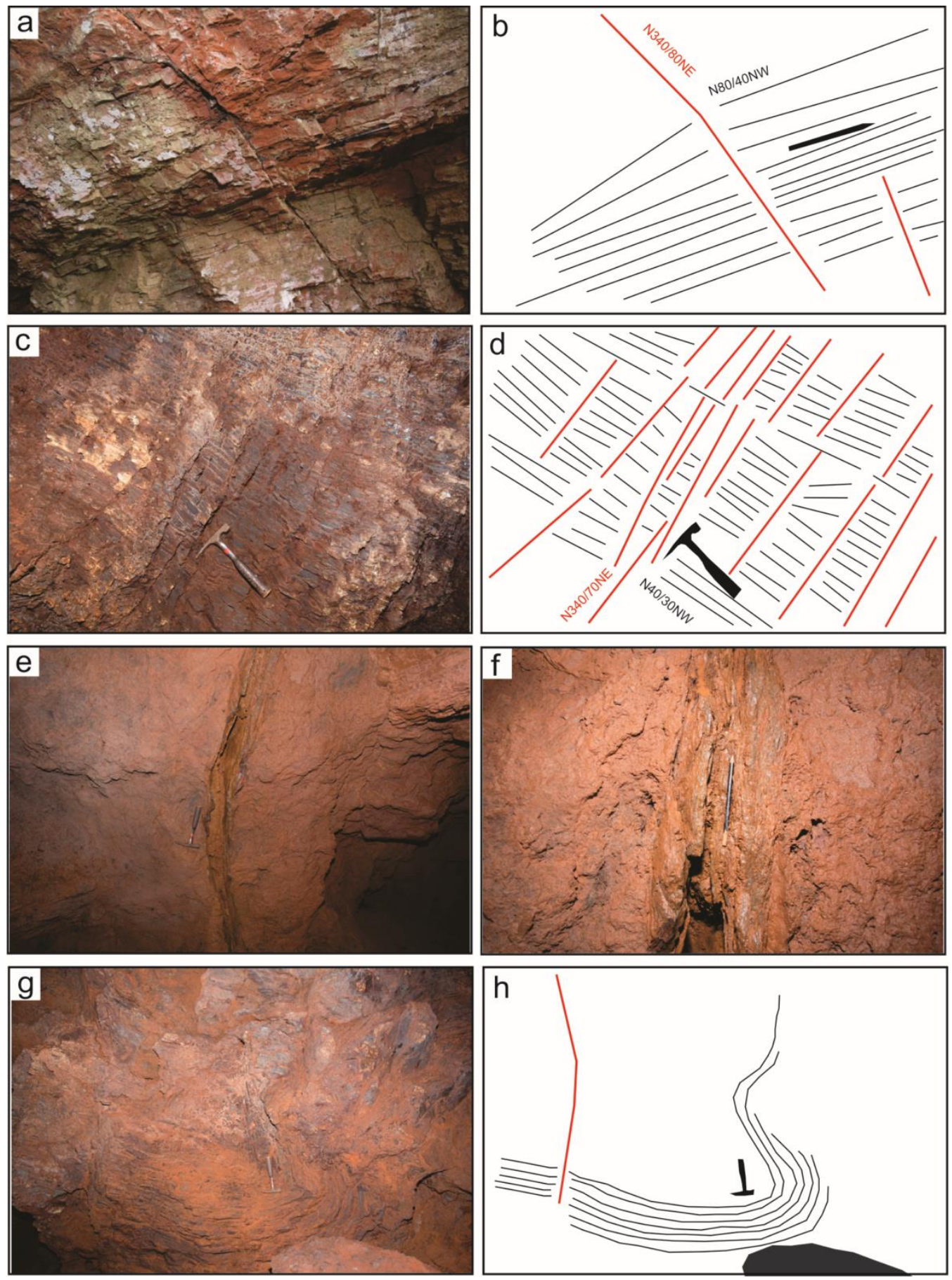

Figura 14. Feições litoestruturais. a) e b) família de fraturas N340\%/80NE seccionando o bandamento N80\%/40NW. c) e d) família de fraturas N340\%/70NE seccionando o bandamento N40\%/30NW. e) e f) fraturas N40\%/Subvertical preenchidas por material ferruginoso. g) e h) dobra na Formação Ferrífera Bandada. 


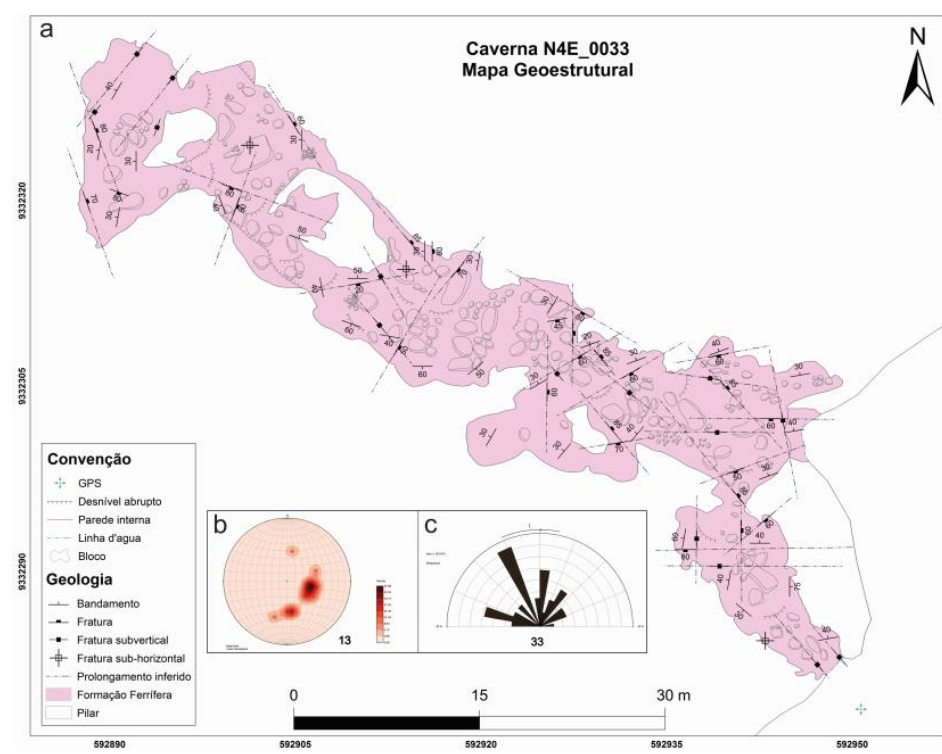

Figura 15. Em a, o mapa geoestrutural da caverna N4E_0033. b) diagrama de polos correspondente a 13 medidas de bandamento. c) diagrama de rosetas com 33 medidas de fraturas.

\subsubsection{Caverna N4E_0092}

A caverna N4E_0092 se desenvolveu sob escarpamento rochoso irregular, com altura média de $6 \mathrm{~m}$. É constituída por apenas um conduto, amplo, de paredes e teto irregulares. Crostas ferruginosas foram observadas nas paredes. A foto da Figura 16 apresenta a única entrada da caverna.

É hospedada essencialmente em FFB com bandamento preservado caracterizado pela alternância de bandas de óxido e hidróxido de ferro, de até $1 \mathrm{~cm}$ de espessura. Entre as bandas observase filmes de minerais neoformados, goethita, produto da alteração da própria rocha. Em algumas porções notam-se bolsões de canga em meio a FFB.

Esta caverna se desenvolveu seguindo orientação aproximadamente $\mathrm{N}-\mathrm{S}$, como mostra a Figura 18a. Esta direção corresponde ao eixo de uma grande dobra que controla o desenvolvimento da caverna. O bandamento apresenta-se com variação de NW para $\mathrm{NE}$, do terço inicial para o terço distal, respectivamente, com mergulhos moderados, o diagrama de polos é apresentado na Figura 18b. Por sua vez, as fraturas se orientam segundo NNW-SSE, bem como, ENE-WSW e WNW-ESE (Figura 18c). O nível de deformação afetou a caverna de forma heterogênia, onde se observam porções com o bandamento preservado (Figura 17a) e por vezes dobrado (Figura 17b), com espaços vazios entre as bandas de ferro, resultado dos processos de remobilização das bandas de sílica, e pontos em que as bandas são cortadas por famílias de fraturas que se intersectam, com espaçamento centimétrico entre estas (Figura 17c). Tais fraturas tendem a cortar o bandamento de forma perpendicular (Figura 17d), em alguns casos pode ocorrer o preenchimento destas por material silicoso. As Figuras 17e e $17 \mathrm{f}$ apresentam a FFB dobrada sendo cortada por fraturas de atitude N350\%/40SW. Em casos mais extremos podem ocorrer paralelas ao plano de bandamento, o que pode acarretar em desplacamento de blocos (Figura 17g e 17h).

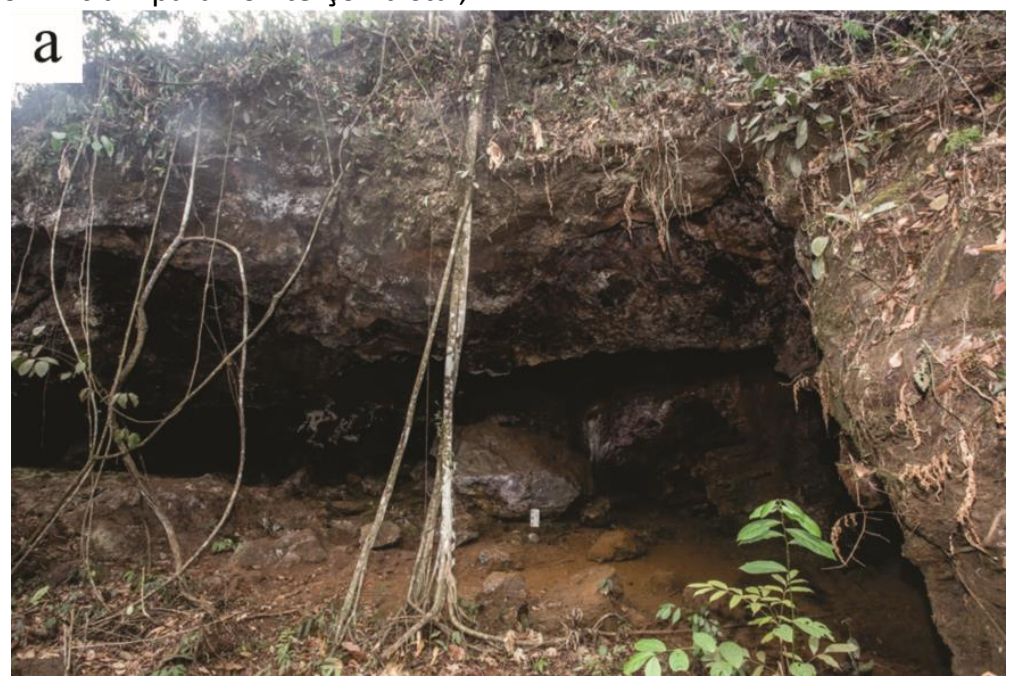

Figura 16. Foto da entrada da caverna N4E_0092. 

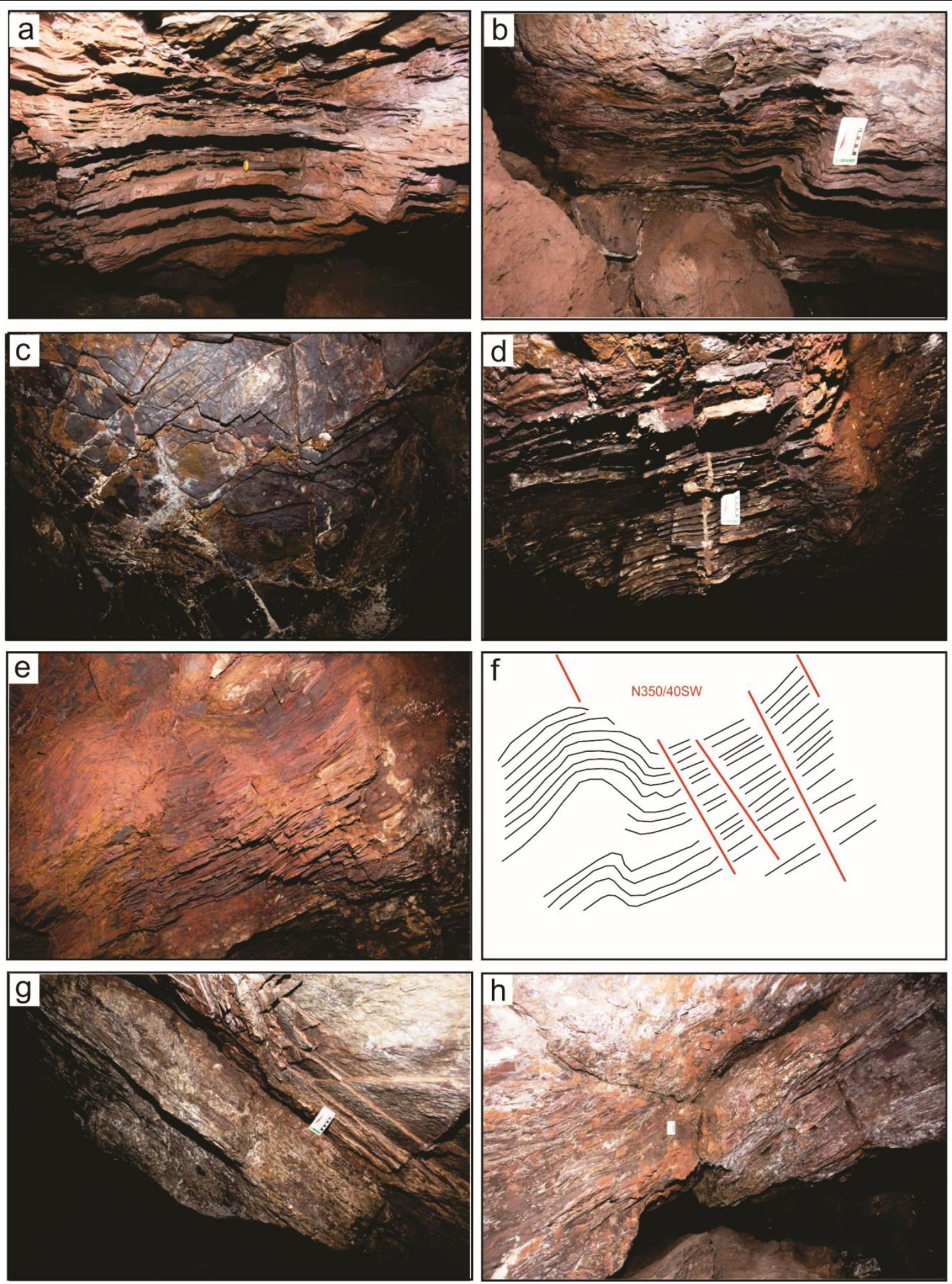

Figura 17. Feições litoestruturais. a) foto da FFB mostrando as bandas de hematita intercaladas com espaços vazios. b) bandamento dobrado. c) famílias de fraturas no perpendiculares ao plano do bandamento. d) fratura subvertical preenchida por sílica seccionando a FFB. e) e f) fratura $\mathrm{N350}$ /40SW cortando a FFB dobrada. g) e h) mostrando o rompimento no paralelo ao plano do bandamento.

Caverna N4E_0093A caverna apresenta 45,5m de projeção horizontal. Possui duas entradas que se conectam através de um conduto. A principal tem cerca de $3 \mathrm{~m}$ altura por $2,5 \mathrm{~m}$ de extensão e se desenvolve em um afloramento de aproximadamente $7 \mathrm{~m}$ de extensão (Figura 19a). Um bloco abatido obstrui parcialmente a entrada. A segunda entrada ocorre em uma linha d'agua com cerca de $10 \mathrm{~m}$ de extensão (Figura 19b). Nas duas, o piso se da em nível inferior, sendo este, geralmente plano, com algumas partes pouco inclinadas. As paredes são irregulares assim como o teto, que apresenta pontões de FFB. 


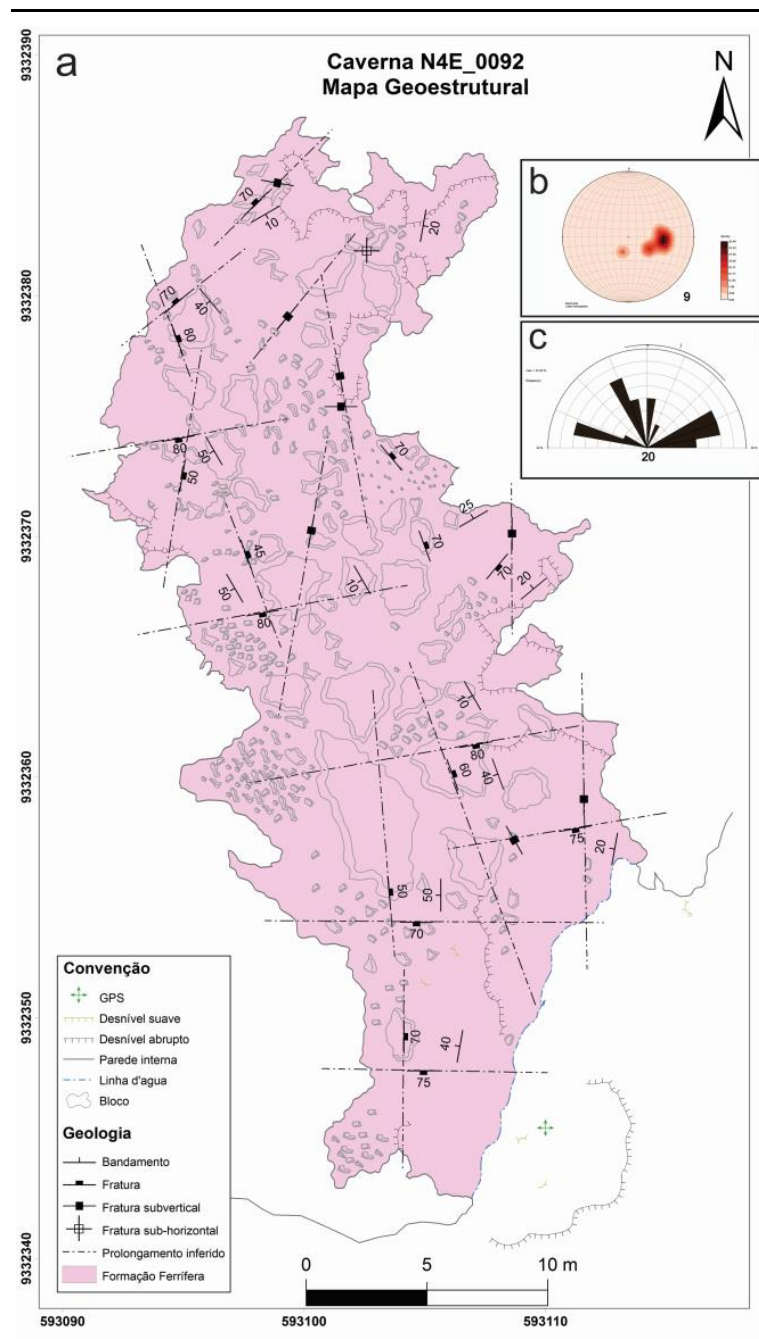

Figura 18. Em a, o mapa geoestrutural da caverna N4E_0092. b) diagrama de polos correspondente a 9 medidas de bandamento.

c) diagrama de rosetas com 20 medidas de fraturas.

Desenvolve-se em sua totalidade na FFB. As bandas de hematita variam de milimétricas a centimétricas (Figura 20a e 20b). É possível notar em algumas porções a presença de goethita.

A caverna possui controle estrutural marcante.
Sua forma retilínea apresenta desenvolvimento pronunciado na direção NE-SW e secundária para NW-SE (Figura 21a). As principais estruturas descritas foram bandamento e fraturas. O primeiro ocorre em toda a caverna e ainda preserva sua orientação original, desta forma facilita a tomada de atitudes. Todos os pontos medidos apresentaram direção NE-SW com mergulho moderado para NW (Figura 21b). Já o diagrama de rosetas (Figura 21c) evidencia que as fraturas se apresentam aproximadamente paralelas e perpendiculares à direção do bandamento como mostram as Figuras 20 c e 20d. A família principal se orienta segundo NESW (45/40NE) e uma segunda direção ocorre para NW-SE (310/Sv) de forma subvertical. Por conta da intersecção de fraturas com o bandamento, que pode gerar desplacamento de blocos, é possível denotar gênese endógena, uma vez que, a direção da caverna segue a mesma das estruturas principais.

A influência que estruturas descontínuas desempenham sobre o controle de cavernas já vem sendo relatada em alguns trabalhos. Maurity e Kotschoubey (1995) afirmaram que fraturas atuam como condutos naturais para a água percolar, controlando desta forma, as direções das principais galerias. Por outro lado, Piló e Auler (2009) relatam que algumas cavernas de Carajás não possuem controle estrutural marcante, o que pode ser atribuído ao fato terem sido formadas por acomodação de blocos ou ainda estarem ligadas à porosidade da rocha (canga). Portanto, as cavernas de Carajás podem ser divididas em dois grupos, onde o primeiro corresponde àquelas formadas pela acomodação de blocos ou ligadas à porosidade, sem controle evidente. E o segundo formado pelas cavernas que apresentam alguma forma de controle, principalmente por estruturas.
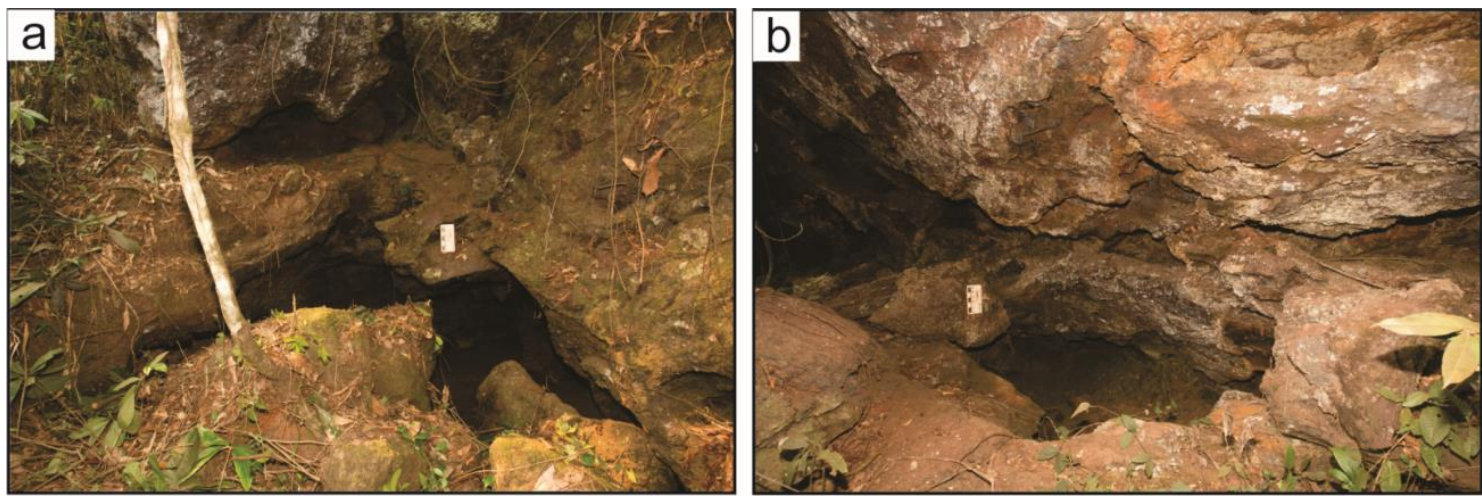

Figura 19. Fotos das entradas da caverna N4E_0093. a) entrada na porção nordeste. b) a sudoeste da caverna. 

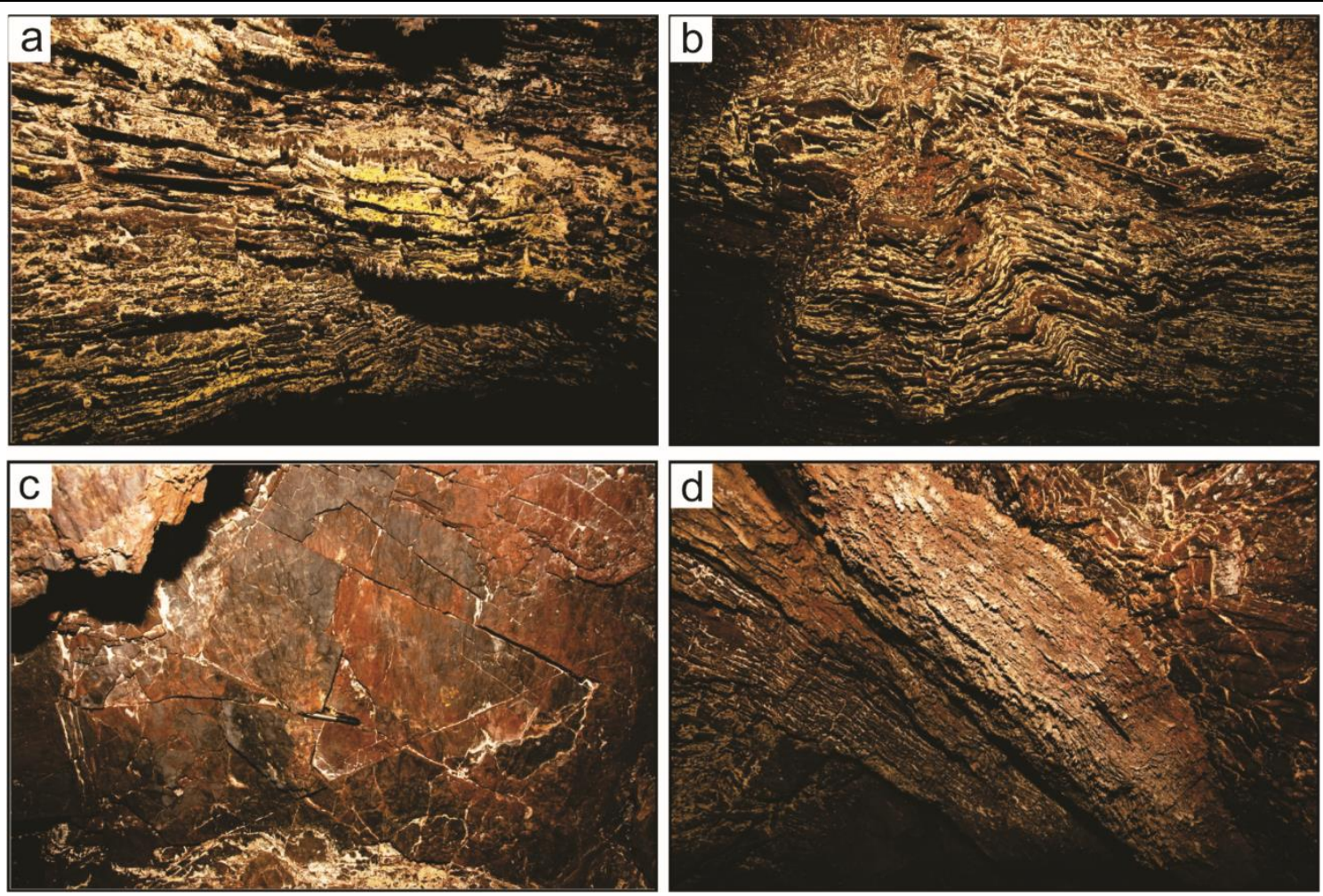

Figura 20. Feições litoestruturais. a) e b) foto do bandamento na FFB. c) e d) fraturas perpendiculares e paralelas ao plano de bandamento, respectivamente.

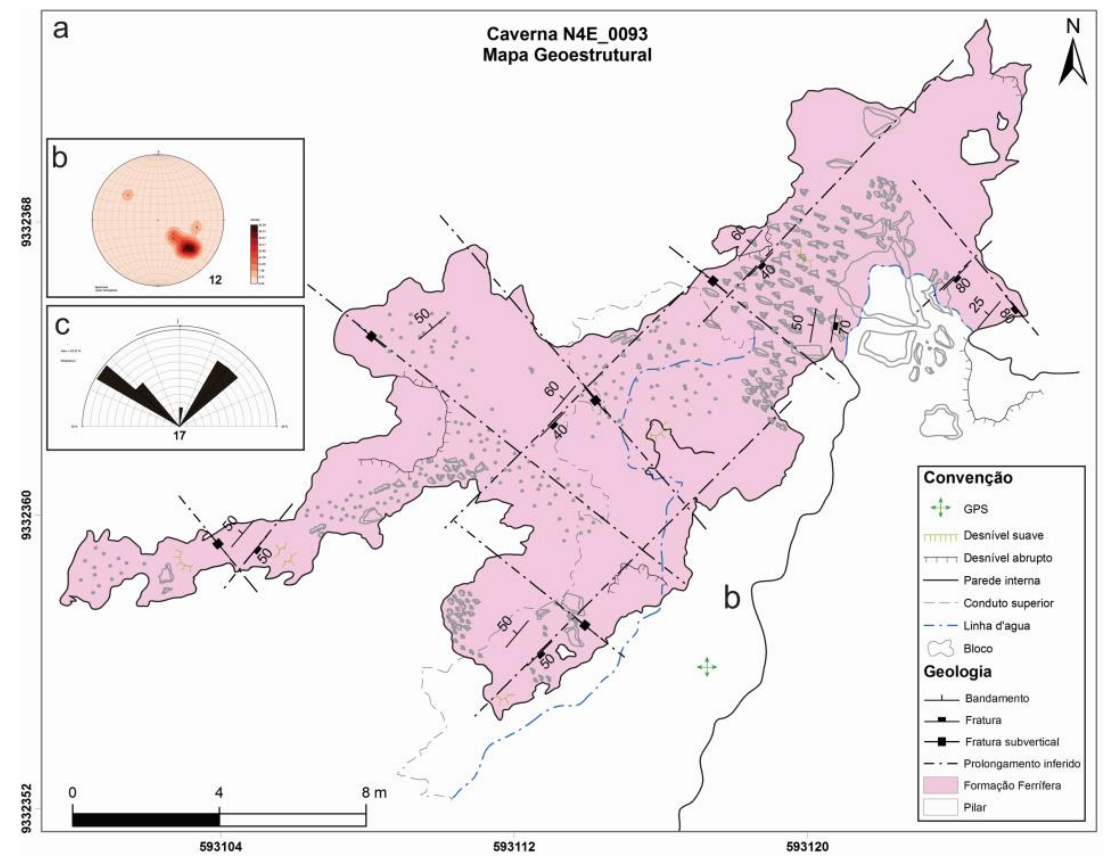

Figura 21. a) o mapa geoestrutural da caverna N4E_0093. b) diagrama de polos correspondente a 12 medidas de bandamento. c) diagrama de rosetas com 17 medidas de fraturas.

As cinco cavernas descritas acima apresentam controle estrutural evidente, seja ele ocasionado pela direção do bandamento na FFB, ou por fraturas que as cortam e possibilitam a percolação de fluidos. A intersecção entre essas estruturas são responsáveis por gerar instabilização no maciço rochoso que acarreta em desplacamento de blocos e consequente ampliação das cavernas.

A Figura 22a e 22b apresentam respectivamente, todas as medidas de bandamento coletadas nas cinco cavernas avaliadas, assim como, as medidas de fraturas. O diagrama de rosetas é diferente do que se esperaria na ocasião das cavernas descritas terem sido influenciadas por eventos tectônicos recentes. 


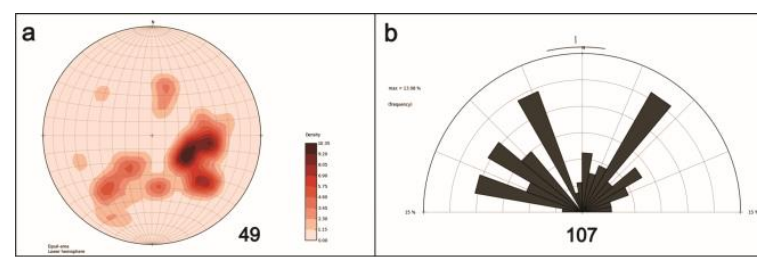

Figura 22. a) diagrama de polos correspondente a 49 medidas de bandamento coletadas nas cinco cavernas. b) diagrama de rosetas com 107 medidas de fraturas para as mesmas cavernas.

A partir dos dados apresentados se torna inconsistente estabelecer relação entre as cavernas estudadas e a influência de eventos tectônicos recentes. Pois a Figura 27b mostra que as principais direções de fraturas ocorrem para NW e NE, ao contrário do que é relatado na literatura, a qual discorre que as estruturas mais recentes da região de Carajás seguem o trend N-S e E-W. No entanto, como o universo de cavidades na região é vasto, torna-se imprescindível a realização de estudos neste âmbito a fim de tal relação. A princípio pode se afirmar que elas possuem controle estrutural marcante.

\section{CONCLUSÕES}

- A caracterização das cinco cavernas apresentadas demostrou que todas apresentam controle por estruturas, sejam elas fraturas ou a direção dos planos de bandamento. Assim, é possível afirmar que elas possuem seu desenvolvimento e ampliação atrelados a alguma descontinuidade que facilite a percolação de fluidos e/ou cause desplacamento de blocos.

- Cavernas em FFB no geral apresentam controle estrutural marcante.

- A comparação entre direção de condutos e a orientação dos canais de drenagem de primeira ordem, os quais podem representar os eventos tectônicos mais recentes da área, atestou que nas cavernas descritas não há influência de estruturas tectônicas recentes. Em contrapartida, cavernas que sejam desenvolvidas essencialmente em canga podem apresentar tal influência, uma vez que, esse material tem sua gênese ligada ao inicio do cenozoico.

\section{CONSIDERAÇÕES FINAIS}

O estudo de análise geoestrutural em cavernas é bastante complexo e ainda pouco explorado, se comparado à importância econômica que essas feições possuem. Assim, é recomendada uma análise mais aprofundada a respeito do tema, principalmente no que compete à influência de estruturas neotectônicas.

\section{REFERÊNCIAS}

Bemerguy R.L, Espírito Santo C. V., Costa J. B. S., Rozal E. O. 2000. Aspectos Morfoestruturais e Neotectônicos da Região da Serra dos Carajás (Sudeste do Estado do Pará). UNESP, Geociências, São Paulo, 19(1): 35-49.

CABRAL, E.S., MACAMBIRA, J.B., ABREU, S.S., 2016. Geologia e petrografia de formações ferríferas bandadas em cavernas da Serra Sul, Carajás - PA. Revista Espeleo-Tema, v 27, no 1, p. 45-56.

Costa J.B.S., Igreja H.L.S., Borges M.S., Hasui Y. 1991. O quadro tectônico regional do Mesozóico na região Norte do Brasil. In: 3o Simpósio de Geologia da Amazônia, Belém. Anais... Belém: SBG, p. 166-178

Costa J.B.S., Hasui Y., Bemerguy R.L., Borges M.S., Ferreira Júnior C.R.P., Bezerra P.E.L., Costa M.L., Fernandes J.M.G. 1996. Neotectônica da Região Amazônica: Aspectos tectônicos, geomorfológicos e deposicionais. Geonomos. Revista de Geociências, 4(2): 23-44.

Costa, U.A.P., 2006. Avaliação dos processos geradores do minério de Ferro da serra norte de carajás, sudeste do Pará. Centro de Geociências da Universidade Federal do Pará Dissertação de mestrado. 110 p.

Dall'Agnol R., Oliveira M. A., 988 J. A. C., Althoff F. J., Leite A. A. S., Oliveira D. C., Barros C.E.M. 2006. Archean and Paleoproterozoic granitoids of the Carajás metallogenic province, eastern Amazonian craton. Em: Symposium on Magmatism, Crustal Evolution, and Metallogenesis of the Amazonian Craton. Belém, PRONEX-UFPA/SBG, p. 97-150.

Dutra G.M. 2013. Síntese dos Processos de Gênese de Cavidades em Litologias de Ferro. Anais do 32 ․ Congresso Brasileiro de Espeleologia. Barreiras-BA, p. 415-426.

Feio G.R.L. 2011. Magmatismo Granitóide Arqueano da Área de Canaã dos Carajás: Implicações para a Evolução Crustal da Província Carajás. Tese de Doutorado, Instituto de Geociências, Universidade Federal do Pará, 190 p.

Gibbs A.K., Wirth K.R. 1990. Geologic Setting of the Serra dos Carajás Iron deposits, Brazil - Ancient Banded Iron Formations. Theophrastus publications, S.A., Greece, p. 83102.

Gibbs A.K., Wirth K.R., Hirata W.K., Olzewski W.J. 1986. Age and composition of the Grão Pará Group volcanics, Serra dos Carajás. Revista Brasileira de Geociências, 16: 201-211.

Krymsky R., Macambira J. B., Macambira M. J. B. 2002. Geocronologia U-Pb em zircão de rochas vulcânicas da Formação Carajás, Estado do Pará. Em: Anais 2o Simpósio Sobre Vulcanismo e Ambientes Associados. Belém, p. 41.

Macambira J.B. 2003. O ambiente deposicional do Grupo Grão Pará-Carajás. Tese de Doutorado, Instituto de Geociências, Universidade Estadual de Campinas, Campinas, 212 p.

Macambira J. B., Ramos J. F. F., Assis J. F. P., Figueiras A. J. M. 1990. Projeto Serra Norte, Projeto Pojuca: relatório final. Belém, UFPA, DOCEGEO, SEPLAN, DNPM, p. 150.

Maurity C.W. \& Kotschoubey B. 1995. Evolução recente da cobertura de alteração no Platô N1- Serra dos Carajás-PA. Degradação, pseudocarstificação, espeleotemas. Boletim do Museu Paraense Emílio Goeldi, Série Ciências da Terra, 7: 331-362.

Plló L.B. \& Auler, A. 2009. Geoespeleologia das cavidades em rochas ferríferas da região de Carajás, PA. Anais do 30 은 Congresso Brasileiro de Espeleologia. Montes Claros. SBE, p.181-186.

Pinheiro R.V \& Holdsworth R. 2000. Evolução tectonoestratigráfica dos sistemas transcorrentes Carajás e Cinzento, 
Cinturão Itacaiúnas, borda leste do cráton Amazônico, Pará. Revista Brasileira de Geociências.

Resende N.P. \& Barbosa A.L.M. 1972. Relatório de Pesquisa de Minério de Ferro, Distrito Ferrífero da Serra dos Carajás. Pará, $119 \mathrm{p}$.

Strahler A.N. 1952. Hypsometric (areal-altitude) analysis of erosional topography. Geol. Soc. Am. Bull., 63: 1117-1142.

Souza C.I.J. Kotschoubey B. 1991. Alguns aspectos micromorfológicos e gênese da cobertura residual sobre rochas sedimentares da aba norte da serra dos carajás, Pará. In: Simp. Geol. Amaz., 3, Belem, Anais..., SBG/NN v.1. p.569583.

Vasconcelos P.M. 1992. Timing and rates of evolution of hydrochemical systems in tropical humid environments by application of $40 \mathrm{Ar} / 39 \mathrm{Ar}$ absolute dating of K-bearing weathering product minerals. Ph. D. Thesis, Univ. California, Berkeley,

241 